\title{
An evidence-based multidisciplinary approach to the management of hepatocellular carcinoma (HCC): The Alberta HCC algorithm
}

\author{
Kelly W Burak MD FRCPC MSc(Epid) ${ }^{1}$, Norman M Kneteman MD FRCSC MSc ${ }^{2}$
}

KW Burak, NM Kneteman. An evidence-based multidisciplinary approach to the management of hepatocellular carcinoma (HCC): The Alberta HCC algorithm. Can J Gastroenterol 2010;24(11):643-650.

Hepatocellular carcinoma (HCC) is one of only a few malignancies with an increasing incidence in North America. Because the vast majority of HCCs occur in the setting of a cirrhotic liver, management of this malignancy is best performed in a multidisciplinary group that recognizes the importance of liver function, as well as patient and tumour characteristics. The Barcelona Clinic Liver Cancer (BCLC) staging system is preferred for $\mathrm{HCC}$ because it incorporates the tumour characteristics (ie, tumour-node-metastasis stage), the patient's performance status and liver function according to the Child-Turcotte-Pugh classification, and then links the BCLC stage to recommended therapeutic interventions. However, the BCLC algorithm does not recognize the potential role of radiofrequency ablation for very early stage HCC, the expanding role of liver transplantation in the management of HCC, the role of transarterial chemoembolization in single large tumours, the potential role of transarterial radioembolization with ${ }^{90}$ Yttrium and the limited evidence for using sorafenib in ChildTurcotte-Pugh class B cirrhotic patients. The current review article presents an evidence-based approach to the multidisciplinary management of HCC along with a new algorithm for the management of HCC that incorporates the BCLC staging system and the authors' local selection criteria for resection, ablative techniques, liver transplantation, transarterial chemoembolization, transarterial radioembolization and sorafenib in Alberta.

Key Words: Ablation; Embolization; Hepatocellular carcinoma; Liver transplantation; Sorafenib; Surgery

【epatocellular carcinoma (HCC) is a leading cause of 1 cancer-related deaths worldwide, being the fifth most common cancer and the third most important cause of cancerrelated mortality in men (1). In North America, HCC is one of only four malignancies with an incidence that increased by more than 2\% per year between 1975 and 2006, including a recent annual increase of $5.4 \%$ between 2002 and 2006 (2). There is evidence that the incidence of HCC is on the rise in Canada. Age-standardized incidence rates of HCC in Canada increased by $3.4 \%$ per year in men, and $1.2 \%$ per year in women between 1969 and 1997 (3). Incidence rates in Canada over the next five years (2011 to 2015) are predicted to be as high as 18.5 per 100,000 (7672 new cases per year) for men and 4.1 per 100,000 (1709 new cases per year) for women 40 to 84 years of age (4). This is due, in large part, to the burden of chronic hepatitis $\mathrm{C}$

\section{Une démarche multidisciplinaire probante pour la prise en charge du carcinome hépatocellulaire} (CHC) : L'algorithme du CHC de l'Alberta

Le carcinome hépatocellulaire (CHC) est l'une des quelques tumeurs malignes à l'incidence croissante en Amérique du Nord. Puisque la majorité des $\mathrm{CHC}$ se déclarent en présence d'un foie cirrhotique, leur prise en charge est mieux assurée par un groupe multidisciplinaire qui reconnaît l'importance de la fonction hépatique, les caractéristiques du patient et celles de la tumeur. Le système d'établissement des phases du cancer hépatique de la clinique de Barcelone (BCLC) est favorisé pour le $\mathrm{CHC}$ parce qu'il inclut les caractéristiques de la tumeur (p. ex., phase tumeur-nodule-métastase), le rendement du patient et la fonction hépatique conformément à la classification de Child-TurcottePugh, puis lie le système BCLC aux interventions thérapeutiques recommandées. Toutefois, l'algorithme BCLC ne tient pas compte du rôle potentiel de l'ablation par radiofréquence aux toutes premières phases du CHC, du rôle croissant de la greffe du foie dans la prise en charge du $\mathrm{CHC}$, du rôle de la chimioembolisation transartérielle en cas de tumeurs uniques importantes, du rôle potentiel de la radioembolisation transartérielle par ${ }^{90}$ Yttrium et des données limitées sur l'usage du sorafénib chez les patients cirrhotiques de catégorie B selon la classification de Child-Turcotte-Pugh. La présente analyse propose une démarche probante pour la prise en charge multidisciplinaire du $\mathrm{CHC}$ de même qu'un nouvel algorithme de prise en charge du $\mathrm{CHC}$ qui intègre le système BCLC aux critères de sélection locaux des auteurs à l'égard de la résection, des techniques d'ablation, de la greffe du foie, de la chimioembolisation transartérielle, de la radioembolisation transartérielle et du sorafénib en Alberta.

virus infection (the leading cause of HCC in North America [5]) and to increased immigration of patients from countries with high endemic carrier rates for chronic hepatitis B virus (HBV, the leading cause of $\mathrm{HCC}$ worldwide [1]). In recent years, we have seen an increased burden of HCC in the surgical programs in Alberta. A recent review (6) of hepatic resections in the Calgary Health Region reported a dramatic increase in liver resections performed between 1991 and 2004. HCC is also an increasingly common indication for liver transplantation (LT) in Alberta (Figure 1). From 1989 to 1999, 7.3\% of adult LTs in Alberta were performed for HCC; this increased to $19.9 \%$ for the years 2000 to 2009 ( $\mathrm{P}<0.0001)$. In 2009, 39.3\% of all adult LTs in Alberta were performed for patients with HCC.

The vast majority of HCCs in North America occur in the setting of a cirrhotic liver $(5,7)$. It is, therefore, important that

${ }^{1}$ Liver Unit, Department of Medicine, University of Calgary, Calgary; ${ }^{2}$ Liver Transplant Program, Department of Surgery, University of Alberta, Edmonton, Alberta

Correspondence: Dr Kelly W Burak, University of Calgary Liver Unit, Room 6D35, Teaching, Research and Wellness Building, 3280 Hospital

Drive Northwest, Calgary, Alberta T2N 426. Telephone 403-592-5049, fax 403-592-5090, e-mail kwburak@ucaglary.ca

Received for publication June 14, 2010. Accepted June 21, 2010 


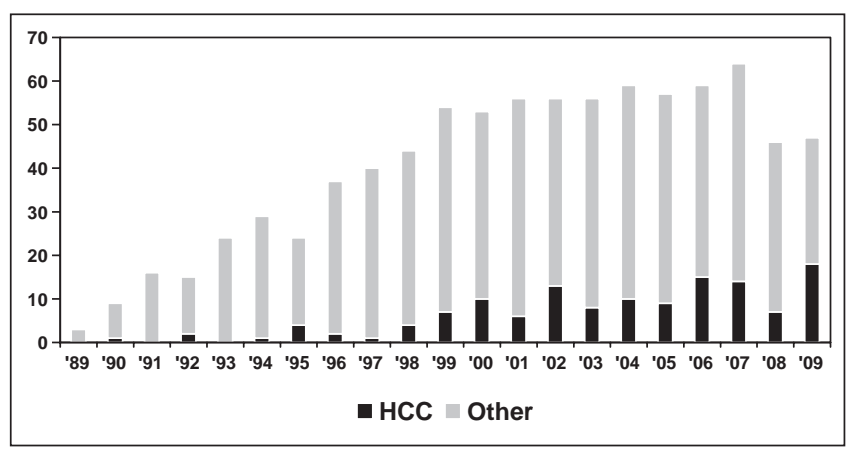

Figure 1) Number of adult liver transplants in Alberta performed for hepatocellular carcinoma (HCC, black bars) and other indications (grey bars) according to year (1989 to 2009)

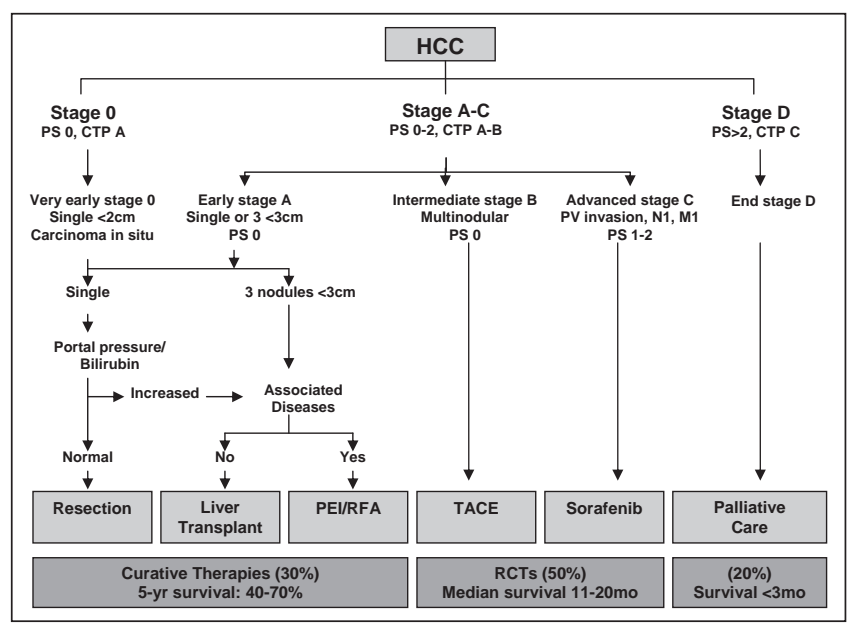

Figure 2) Barcelona Clinic Liver Cancer staging system. CTP ChildTurcotte-Pugh class; HCC Hepatocellular carcinoma; M Metastases; mo Months; N Lymph node; PEI Percutaneous ethanol injection; PS Performance status; PV Portal vein; RCTs Randomized controlled trials; RFA Radiofrequency ablation; TACE Transarterial chemoembolization; yr Year. Adapted with permission from reference 9

clinicians managing $\mathrm{HCC}$ recognize the competing risks for mortality from the tumour and the cirrhosis. The American Association for the Study of Liver Diseases (AASLD) has endorsed a multidisciplinary approach to the management of HCC using the Barcelona Clinic Liver Cancer (BCLC) staging system (7). The BCLC staging system was originally proposed in 1999 (8), and was updated recently to include sorafenib as the standard of care for patients with advanced stage HCC (Figure 2) (9). The BCLC staging system is preferred by many in North America (10) because it takes into account the patient's performance status (PS) (Table 1), liver function according to the Child-Turcotte-Pugh (CTP) classification (Table 2) and the tumour stage according to the modified tumour-node-metastasis staging system. The BCLC algorithm also has the advantage of linking these patient-, tumour- and liver-related factors to specific therapies for HCC.

In late 2001, a multidisciplinary liver tumour group was started at the Tom Baker Cancer Centre in Calgary, Alberta, to deal with an increasing number of patients presenting with HCC. The group, which has grown in size and diversity over the years (Table 3 ), meets on a weekly basis to review imaging and discuss management strategies for these complex patients.
TABLE 1

Eastern Cooperative Oncology Group patient performance status

\begin{tabular}{ll}
\hline $\begin{array}{l}\text { Performance } \\
\text { status }\end{array}$ & Description \\
\hline 0 & Fully active and able to function without restriction \\
1 & Unable to perform physically strenuous activities, but \\
& ambulatory and able to complete work of a light or \\
& sedentary nature \\
& Ambulatory and capable of all self-care but unable to \\
& complete work activities. Up and about more than \\
& $50 \%$ of waking hours \\
& Capable of only limited self-care and/or confined to a \\
& bed or chair for more than $50 \%$ of waking hours \\
& Completely disabled. Unable to manage any self-care. \\
& Totally confined to a bed or chair \\
\hline
\end{tabular}

TABLE 2

Child-Turcotte-Pugh (CTP) classification score

\begin{tabular}{lccc}
\hline Criteria & 1 point & 2 points & 3 points \\
\hline Encephalopathy & Grade 0 & Grade 1-2 & Grade 3-4 \\
Ascites & None & Controlled & Refractory \\
Bilirubin, $\mu \mathrm{mol} / \mathrm{L}$ & $<34$ & $34-50$ & $>50$ \\
Albumin, g/L & $>35$ & $28-35$ & $<28$ \\
International normalized ratio & $<1.7$ & $1.7-2.2$ & $>2.2$ \\
\hline
\end{tabular}

CTP class $A=5$ to 6 points; CTP class $B=7$ to 9 points; CTP class $C=10$ to 15 points

TABLE 3

Multidisciplinary Liver Tumour Group at the Tom Baker Cancer Centre (Calgary, Alberta)

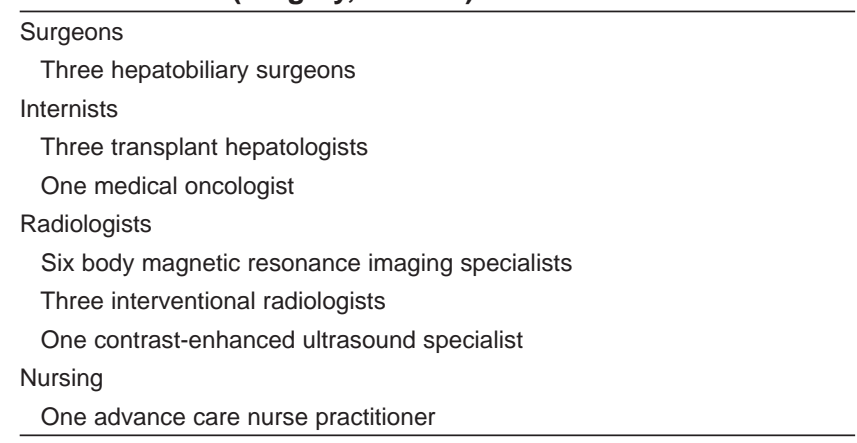

For the most part, since the inception of the Tom Baker Cancer Centre Liver Tumour Group, we have followed the BCLC treatment algorithm. However, within the past few years, there has been emerging evidence that has changed our management of HCC; most importantly, how we list patients for LT in Alberta (Table 4) (11). Furthermore, the BCLC algorithm does not recognize the potential role of radiofrequency ablation (RFA) for very early stage HCC, the role of LT for CTP class C cirrhotic patients with HCC, the role of transarterial chemoembolization (TACE) in single large tumours, the potential role of transarterial radioembolization (TARE) with ${ }^{90}$ Yttrium $\left({ }^{90} \mathrm{Y}\right)$, and the limited evidence for using sorafenib in patients with CTP class B cirrhosis. Therefore, a new algorithm is proposed (Figure 3), which incorporates the basic principles of the BCLC staging system along with important changes in the management of $\mathrm{HCC}$ as currently practiced in Alberta (12). The present review article provides evidence to support 
TABLE 4

Liver transplant criteria for hepatocellular carcinoma patients in Alberta

\begin{tabular}{|c|c|}
\hline \multicolumn{2}{|c|}{ Tumour criteria } \\
\hline Listing & $\begin{array}{l}\text { Total tumour volume } \leq 115 \mathrm{~cm}^{3} \text { AND alpha-fetoprotein } \\
\leq 400 \mathrm{ng} / \mathrm{mL}\end{array}$ \\
\hline Down staging & $\begin{array}{l}\text { Total tumour volume } \leq 250 \mathrm{~cm}^{3} \text { regardless of } \\
\text { alpha-fetoprotein level, who achieve listing criteria } \\
\text { AND remain stable for } 6 \text { months }\end{array}$ \\
\hline \multicolumn{2}{|l|}{ Patient criteria } \\
\hline Age & $\begin{array}{l}\text { Typically younger than } 70 \text { years of age, should have } \\
\text { no comorbidities if } 65 \text { to } 69 \text { years of age }\end{array}$ \\
\hline Medical & $\begin{array}{l}\text { No major cardiopulmonary issues, nonsmoker, } \\
\text { HIV negative, appropriate nutritional status, etc }\end{array}$ \\
\hline Social & $\begin{array}{l}\text { Adequate support, compliance, appropriate } \\
\text { abstinence and rehabilitation if addiction issues* }\end{array}$ \\
\hline
\end{tabular}

*Patients being considered for liver transplantation in which alcohol has played a component in the development of liver disease will only be permitted to undergo liver transplantation workup after they fulfill the criteria for listing including abstinence from alcohol (and in some cases, other illicit drugs including marijuana) for six months with certified attendance at an alcohol rehabilitation centre

the new Alberta HCC algorithm and highlights important differences and improvements over the existing BCLC staging system (Table 5).

\section{DIAGNOSIS OF HCC}

The AASLD guidelines recommend screening for HCC in all cirrhotic patients with ultrasound every six months (7). Screening for chronic carriers of HBV is also recommended (7), and recent nomograms have been published to help identify HBV carriers who may benefit from screening (13). After a nodule is discovered in a cirrhotic liver, a contrast-enhanced study is recommended to search for the typical features of HCC - namely, arterial phase enhancement and portal venous phase washout (7). This can be accomplished with contrastenhanced computed tomography, contrast-enhanced magnetic resonance imaging (MRI) or contrast-enhanced ultrasound. According to the AASLD guidelines (7), typical findings on a single study or atypical findings in association with an alphafetoprotein (AFP) level of greater than $200 \mathrm{ng} / \mathrm{mL}$ can establish the diagnosis of HCC for lesions larger than $2 \mathrm{~cm}$ in size. Concordant findings on two imaging modalities are required for lesions $1 \mathrm{~cm}$ to $2 \mathrm{~cm}$ in size. For lesions smaller than $1 \mathrm{~cm}$, a repeat ultrasound in three months is recommended. A biopsy is required only if imaging is discordant for lesions smaller than $2 \mathrm{~cm}$, or if the AFP level is not elevated and imaging is atypical for lesions larger than $2 \mathrm{~cm}$ (7). It is important to recognize that a biopsy carries an approximately $2 \%$ risk of tumour seeding (14), and the false-negative rate can be greater than $10 \%$ for small lesions (15). This AASLD diagnostic algorithm (7) has recently been prospectively validated for focal lesions $0.5 \mathrm{~cm}$ to $2.0 \mathrm{~cm}$ in size using MRI and contrast-enhanced ultrasound, and has been shown to have a low sensitivity $(33 \%)$ but a very high specificity (100\%) for the diagnosis of HCC (16).

\section{VERY EARLY STAGE HCC (BCLC STAGE 0)}

According to the BCLC staging system, surgical resection is recommended once the diagnosis of a small HCC (smaller than $2 \mathrm{~cm}$ ) is established (7). However, surgery should be reserved for patients with CTP class A cirrhosis to avoid postoperative

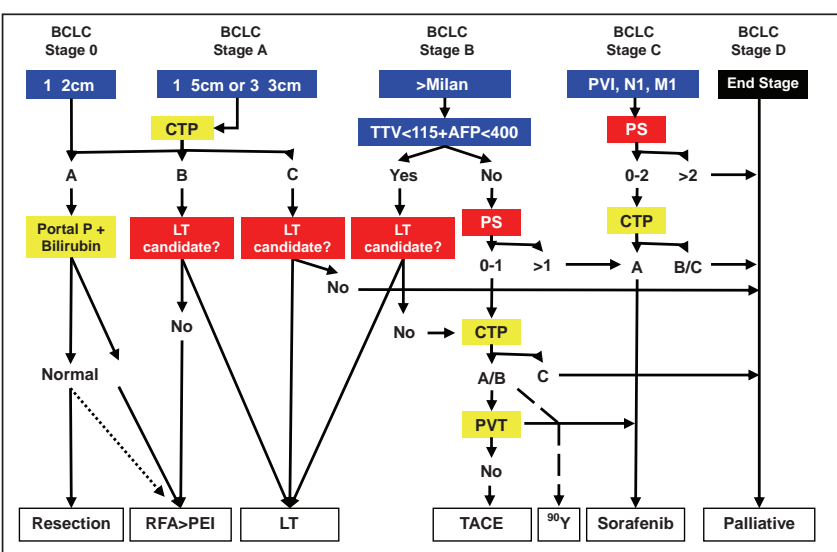

Figure 3) Alberta Hepatocellular Carcinoma algorithm. The algorithm recognizes the importance of tumour properties (blue boxes [size, number, extrahepatic spread and alpha-fetoprotein levels [AFP]), patient characteristics (red boxes [performance status (PS) and candidacy for transplantation]), and liver function (yellow boxes [Child-Turcotte-Pugh (CTP) class along with elevated pressure within or thrombosis of the portal vein]) and links patients to the most appropriate therapy (white boxes). Dotted line represents potential role of radiofrequency ablation (RFA) in very early stage hepatocellular carcinoma. Dashed line recognizes potential role of ${ }^{90}$ Yttrium (Y) transarterial radioembolization with ${ }^{90} \mathrm{Y}$, especially for patients who are not candidates for transarterial chemoembolization (TACE) because of bland portal vein thrombosis (PVT). BCLC Barcelona Clinic Liver Cancer; LT Liver transplantation; M Metastases; Milan Milan criteria (19); N Lymph node; PVI Portal vein invasion; TTV Total tumour volume; Portal P Portal pressure; PEI Percutaneous ethanol injection

liver failure. A five-year survival rate of approximately $70 \%-\mathrm{a}$ benchmark for all curative intent therapies - can be achieved if patient selection is limited to those with normal bilirubin levels and no evidence of portal hypertension (17). Five-year survival drops to approximately $50 \%$ in patients with a bilirubin level above normal $(17 \mu \mathrm{mol} / \mathrm{L}[1 \mathrm{mg} / \mathrm{dL}])$ and falls to $25 \%$ in patients with both elevated bilirubin levels and evidence of portal hypertension (hepatic venous pressure gradient greater than $10 \mathrm{mmHg}$ [17]). It is, therefore, our practice to avoid resection in patients with elevated bilirubin levels, splenomegaly, evidence of varices on imaging or endoscopy, or a platelet count of less than $100 \times 10^{9} / \mathrm{L}$. Surgical resection can carry a risk of significant morbidity and mortality. Resection of HCC carried a 9.6\% risk of perioperative mortality in Calgary during the years 1991 to 2004 (6). However, mortality following resection of HCC decreased from four of 25 cases (16\%) between 1991 and 1999, to only one of 27 cases (3.7\%) from 2000 to 2004 ( $\mathrm{P}=0.13$ ). Reasons for improved outcomes in recent years may include the increasing number of resections, which are now performed primarily by three hepatobiliary surgeons in Calgary, and the multidisciplinary management of these complex patients (6).

There is emerging evidence that RFA may provide a less invasive yet still effective alternative to surgical resection for BCLC stage 0 patients. An Italian study (18) recently subjected 218 patients with a single $\mathrm{HCC} 2 \mathrm{~cm}$ in size or smaller to RFA. After a median follow-up of 31 months, Livraghi et al (18) 


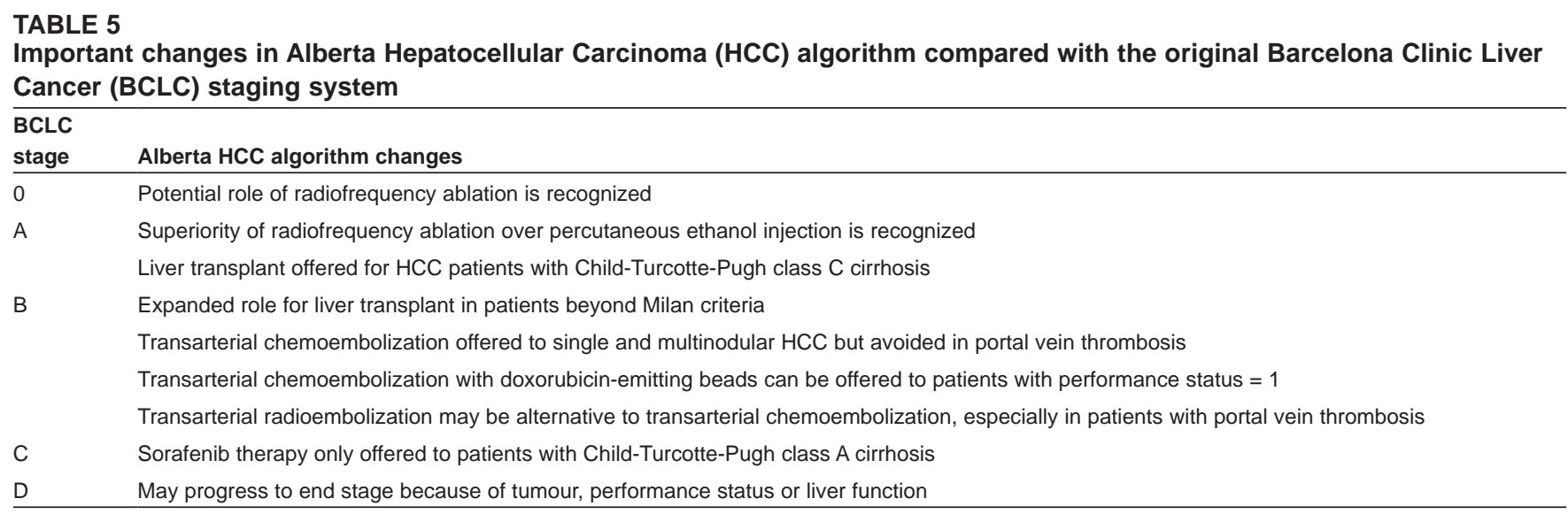

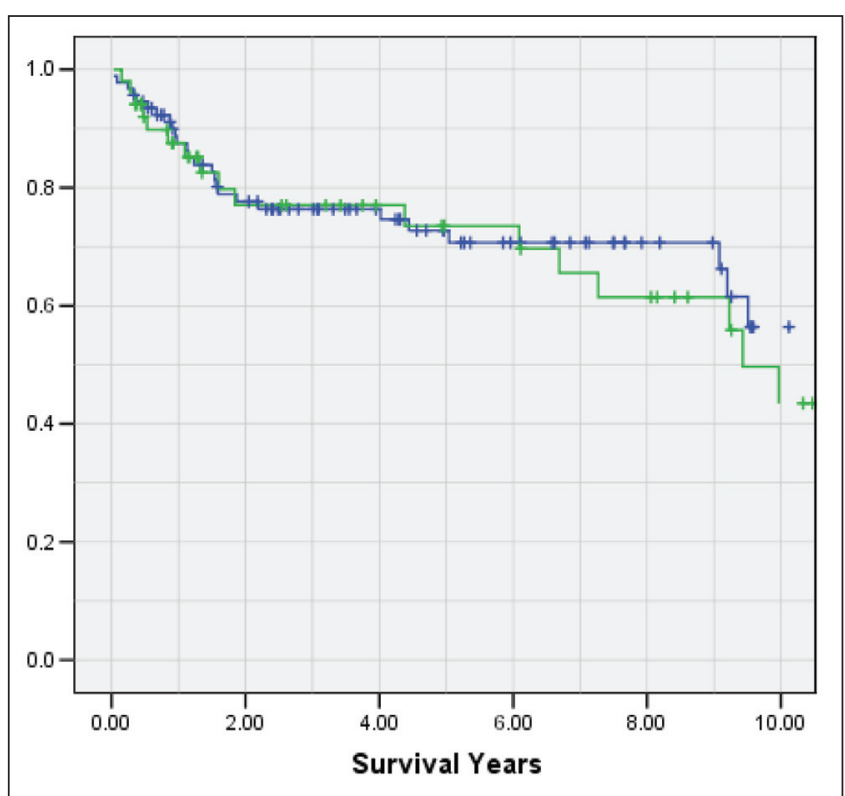

Figure 4) Overall survival after liver transplantation for recipients with hepatocellular carcinoma in Alberta (1989 to 2009), comparing those with Child-Turcotte-Pugh class C cirrhosis $(n=51$, green line) and those with Child-Turcotte-Pugh class A or B cirrhosis $(n=92$, blue line $)$ at the time of transplant

demonstrated a 97\% complete response rate with RFA, with only four patients $(1.8 \%)$ experiencing significant complications (bleeding, tumour seeding or hyperbilirubinemia). Furthermore, a subgroup of patients who would have been candidates for surgical resection $(n=100)$ had a five-year survival rate of $68 \%$ following RFA.

\section{EARLY STAGE HCC (BCLC STAGE A)}

Unfortunately, in western countries, it is estimated that only approximately one-third of patients are candidates for surgical resection, RFA, percutaneous ethanol injection (PEI) or LT (7). According to the BCLC staging system (Figure 2), patients with a single tumour $(5 \mathrm{~cm}$ or smaller) or three tumours $3 \mathrm{~cm}$ or smaller may be considered for curative therapies if they are CTP class A or B. These tumour characteristics, often referred to as the Milan criteria, have been widely adopted as the standard listing criteria for LT after Mazzaferro et al (19) demonstrated acceptable survival and low recurrence rates when these listing criteria were met. According to the BCLC staging system, patients with CTP class C cirrhosis, regardless of their tumour characteristics, are considered to be end stage and should be offered only palliative care. This does not recognize the role of LT in patients with advanced liver disease who have HCC. In Alberta, we transplanted 143 individuals with HCC between 1989 and 2009, of which 40 (28\%) had CTP class A, 52 (36\%) had CTP class B and $51(36 \%)$ had CTP class C cirrhosis at the time of LT. More importantly, the overall five-year survival rate following LT in our program is identical for HCC patients who were CTP class $\mathrm{C}$ compared with those who were CTP class A or B at the time of LT (73.5\% versus $72.7 \%$, respectively) (Figure 4$)$. The Alberta HCC Algorithm (Figure 3), therefore, proposes that patients within the Milan criteria be assigned to the various curative treatment modalities based on their CTP score and whether they are an LT candidate (Table 4). Candidacy for transplantation is decided by a multidisciplinary selection committee that meets weekly in Edmonton, Alberta, and teleconferences with Calgary. The patient's age (typically younger than 70 years of age), comorbidities (eg, cardiopulmonary disease, smoking, diabetes or renal disease), nutritional state (eg, poor nutrition or morbidly obese), and social factors (eg, adequate support, compliance, abstinence from alcohol and completion of an appropriate rehabilitation program) are all factors that determine a patient's candidacy for LT. LT is the only curative option for patients with CTP class C cirrhosis because this surgical modality treats both the cancer and the liver failure. The prognosis is extremely guarded in CTP class C cirrhotic patients who are not candidates for LT because such patients are too ill to undergo TACE or receive sorafenib chemotherapy. Percutaneous ablative therapies are associated with increased risk in patients with poorly controlled ascites and coagulopathy, and the overall prognosis in such patients may relate more to the liver failure than the presence of a small HCC.

In cirrhotic patients, surgical resection can be considered as long as patients are otherwise fit for surgery and have reasonable liver function (CTP class A, normal bilirubin levels and no portal hypertension). Although the Milan criteria are not strictly applied to candidacy for surgical resection, a recent analysis (20) suggests that larger tumours (which are more likely to have microvascular invasion) and patients with many 
tumours are more likely to experience recurrence after curative resection. As with BCLC stage 0 , some patients with early stage HCC (within Milan criteria) may also be considered for RFA as an alternative to surgery. A randomized controlled trial (RCT) published by Chen et al (21) in 2006, randomly assigned 180 subjects with CTP class A cirrhosis and a single HCC $5 \mathrm{~cm}$ or smaller to RFA versus surgery, and found similar four-year survival rates (67.9\% versus $64.0 \%$, respectively) in the two groups. However, this study has been criticized because 19 subjects who were randomly assigned to RFA withdrew their consent and subsequently underwent resection. Another RCT, published in Chinese (22), randomly assigned 105 patients with a single HCC $5 \mathrm{~cm}$ or smaller or three lesions $3 \mathrm{~cm}$ in size or smaller to surgical resection or ablation (with microwave or radiofrequency), and found similar overall three-year survival (86.4\% versus $87.1 \%$, respectively) but better disease-free survival in the surgery group (82.4\% versus $51.3 \%$, respectively; $\mathrm{P}=0.128)$. Such an outcome reinforces the importance of sufficient follow-up in survival analysis. An analysis of 7185 patients, from the Japanese nationwide database (three or fewer tumours, $3 \mathrm{~cm}$ or smaller, CTP class A or B) found similar overall short-term survival rates when comparing surgical resection with RFA and PEI; however, two-year recurrence rates were significantly lower following resection $(35.5 \%, \mathrm{n}=2857)$ than with RFA $(55.4 \%$, $\mathrm{n}=3022)$ and PEI (73.3\%, $\mathrm{n}=1306)$ (23). While these initial studies continue to support the superiority of outcomes with surgery, further RCTs are underway, which will hopefully better define the role of RFA versus surgery in patients with early stage HCC and well-compensated cirrhosis. Although RFA remains a reasonable alternative in some patients who may not otherwise be candidates for surgery due to age or comorbidities, surgical resection does appear to offer a clear advantage in long-term disease-free survival, especially for tumours larger than $2 \mathrm{~cm}$.

Patients with CTP class B cirrhosis, who are not candidates for LT (because of age, comorbidities or social factors), should undergo therapy with RFA. The Alberta HCC algorithm recognizes RFA as the preferred percutaneous ablative technique (RFA over PEI). Recent meta-analyses $(24,25)$ have found that RFA is associated with higher success and lower recurrence rates, and provides improved three-year survival rates compared with PEI. We only perform PEI in patients who have failed RFA therapy or in those who are likely to encounter problems with RFA due to tumour location (HCC adjacent to blood vessels where heat sink may occur, for tumours near the gallbladder, or for subcapsular HCC adjacent to the heart or colon). In general, the Milan criteria also apply to our selection of patients for RFA therapy. Although single tumours up to $5 \mathrm{~cm}$ in size can be potentially ablated with RFA, the recurrence rate is significant for tumours that are larger than $3 \mathrm{~cm}$. A large study from Hong Kong (26) of 273 patients with 357 HCC nodules demonstrated that a tumour size of larger than $2.5 \mathrm{~cm}$ was the most important risk factor for local recurrence. Although percutaneous ablative techniques can be used for multiple lesions, we typically only offer RFA to patients with three or fewer tumours and transition patients with multinodular HCC to TACE (Figure 3). A recent meta-analysis of RCTs (27) suggested that the combination of PEI and TACE improves outcomes in larger HCCs.
LT is the preferred option for patients within the Milan criteria because in addition to treating liver failure, it removes the HCC along with the cirrhotic liver, which is prone to HCC recurrence. After surgical resection, recurrence rates of approximately $40 \%$ at two years and $70 \%$ at five years have been reported (17). Conversely, Mazzaferro et al (19) reported 85\% recurrence-free, four-year survival following LT for patients within the Milan criteria. The University of Alberta (UofA, Edmonton, Alberta) recently reported its outcomes in 70 patients with HCC who received sirolimus-based immunosuppression following LT (28). Only two of 34 recipients (6\%) within the Milan criteria experienced tumour recurrence compared with six of 36 recipients $(17 \%)$ who exceeded the Milan criteria (28). A recent review of the Scientific Registry of Transplant Recipients (SRTR) database demonstrated sirolimus-based maintenance therapy to be associated with improved survival after LT for HCC (five-year post-LT survival rate of $83.1 \%$ versus $68.7 \%$; $\mathrm{P}<0.05$ ) (29). Although this drug has a United States Food and Drug Administration 'black box' warning over concerns regarding hepatic artery thrombosis following LT, this has not been our experience in Alberta, and we continue to use sirolimus-based immunosuppression in the majority of our LT recipients transplanted for HCC.

Whether patients with CTP class A cirrhosis should receive LT instead of surgical resection remains an area of debate. Although never compared directly in a randomized trial, the Barcelona Clinic has analyzed their results for surgical resection and LT in an intent-to-treat (ITT) manner (17). The five-year survival rates for resection and LT were nearly identical if patients for resection were carefully selected (CTP class A, normal bilirubin levels and no portal hypertension), and if patients who died or progressed beyond acceptable criteria while awaiting LT were accounted for in the analysis. A recent ITT analysis (30) of patients with HCC listed for LT in the United States (1998 to 2006) found that 18\% were removed from the list due to death or tumour progression, resulting in a five-year ITT survival rate of $61 \%$ versus $32 \%$ for those within or exceeding the Milan criteria. Due to organ donor shortages and long wait times for LT in Alberta, we prefer to offer patients with CTP class A cirrhosis surgical resection (or RFA if high bilirubin levels or portal pressures are present) rather than LT as primary therapy. If patients develop a recurrence or liver failure following RFA or resection, they can then be considered for salvage LT. A recent Markov model (31) suggested that the harm to HCC patients with this strategy outweighs the benefits to nontumour patients on the LT wait list; however, as wait times and the percentage of patients with HCC continue to increase, the strategy of salvage LT becomes more attractive.

\section{INTERMEDIATE STAGE HCC (BCLC STAGE B)}

The BCLC staging system does not recognize the role of LT in patients beyond the Milan criteria. However, LT is able to offer substantially improved survival in patients who are beyond Milan criteria when compared with TACE (32). Many centres, including the University of California San Francisco (UCSF, California, USA), have shown that the Milan criteria may be too restrictive (33). At the UofA, four-year tumourfree survival was similar in patients regardless of whether they exceeded the Milan criteria (73\% versus 75\%) (28). 
Furthermore, an analysis of LT recipients at the UofA, validated in cohorts from Toronto (Ontario) and Colorado (USA), found that a total tumour volume (TTV) greater than $115 \mathrm{~cm}^{3}$ (calculated as $4 / 3 \pi r^{3}$, in which $r=$ radius of the lesion) was a better predictor of survival and tumour recurrence than Milan or University of California San Francisco criteria (34). Additionally, an analysis of 6478 patients transplanted with HCC in the Scientific Registry of Transplant Recipients database (11) determined that a TTV of greater than $115 \mathrm{~cm}^{3}$ and AFP level greater than $400 \mathrm{ng} / \mathrm{mL}$ were independent predictors of survival following LT for HCC. Patients who exceed the TTV and/or AFP cut-offs had three-year post-LT survival rates of less than $50 \%$ (11); therefore, these have been established as the new criteria for LT in Alberta (Table 4). A TTV of $115 \mathrm{~cm}^{3}$ equates to a single tumour size of $6.1 \mathrm{~cm}$; however, patients may have many smaller tumours and still remain within these criteria. Because of the long wait times for LT, it is our practice to offer TACE, RFA and/or PEI to keep patients within acceptable criteria while they await LT. It is, however, still unclear whether such bridging therapies offer a benefit before LT $(35,36)$. In Alberta, patients are awarded Model for End-stage Liver Disease exception points for $\mathrm{HCC}$ as per the United Network for Organ Sharing system (37). Down staging tumours to become acceptable for LT is another strategy that can be used (38). In Alberta, we have proposed down staging of tumours with a TTV of $250 \mathrm{~cm}^{3}$ or less; however, with treatment, patients must reduce their TTV to $115 \mathrm{~cm}^{3}$ or less (with an AFP level of less than $400 \mathrm{ng} / \mathrm{mL}$ ) and remain stable for a period of six months before they can undergo LT (Table 4).

According to the BCLC staging system, TACE is the preferred treatment strategy for patients with multinodular disease and good PS (PS=0). TACE takes advantage of the arterialized blood supply of HCC to delivery chemotherapy and embolic agents to the tumour. Two RCTs published in $2002(39,40)$, demonstrated a benefit of TACE over best supportive care. Patients enrolled in both trials had well-preserved liver function and good PS and, although most had multinodular disease, approximately one-third had large single lesions. Therefore, it is more appropriate to consider TACE for patients who are beyond Milan criteria and who are not candidates for LT (Figure 3). Meta-analyses have confirmed a survival benefit for TACE, with an expected median survival of 18 to 20 months $(41,42)$. Although TACE is generally well tolerated, it is associated with risks of postembolization syndrome (fever, right upper quadrant pain, nausea and vomiting) and may induce liver failure, especially in patients with CTP class B cirrhosis or portal vein thrombosis (PVT) (42). Overall, mortality has been reported in $2.4 \%$ (range $0 \%$ to $9 \%$ ) of patients within one month of TACE (42). In Calgary, from October 2002 to December 2008, we performed 119 TACE procedures in 62 patients and reported a median survival of 20.4 months with periprocedural mortality of $3 \%$ (43). Interestingly, a TTV of greater than $115 \mathrm{~cm}^{3}$ and/or an AFP level of greater than $400 \mathrm{ng} / \mathrm{mL}$ were also associated with reduced survival after TACE in these patients (median survival of 12.3 versus 30.9 months; $\mathrm{P}<0.0001$ ) (44).

There is no consensus on how to perform TACE with regard to the type of chemotherapy or embolic agent, including the role of lipiodol (42). Doxorubicin-emitting beads (DEBs) have been developed to slowly release chemotherapy into the tumour, thereby decreasing systemic toxicity (45). Recently, an RCT (46) of conventional TACE versus DEBs demonstrated no overall significant improvement in tumour response with DEBs, but DEBs were associated with fewer chemotherapy-related sideeffects (primarily alopecia). However, DEBs were associated with significantly improved outcomes in subgroups of difficultto-treat patients, specifically those with CTP class B cirrhosis and poorer PS (PS=1) (46). DEBs have been used for TACE in both Calgary and Edmonton since the beginning of 2009, and an analysis of their cost-effectiveness is underway.

TARE provides internal beta-emitting radiation with ${ }^{90}$ Yttrium particles (TheraSpheres, MDS Nordion, Canada) delivered via angiography. It requires two angiograms, the first to calculate the safe and effective dose of radiation, the shunt fraction through the tumour and to possibly embolize arteries that may lead to inadvertent delivery of radiation to other areas, and a second angiogram to then deliver the ${ }^{90}$ Yttrium particles. Although the upfront costs are higher with TARE, it has the advantage of being performed on an outpatient basis. The selection criteria for TARE are similar to TACE, and although the two modalities have not been compared directly in RCTs, there is emerging evidence from large cohort studies that TARE may provide similar outcomes to those observed with TACE (47). TARE is particularly attractive in patients with PVT, in whom it can be safely administered and has resulted in a 10.4-month (range 7.2 to 16.6 months) survival rate in patients with CTP class A cirrhosis (47). Despite reports of TACE being performed safely in patients with PVT (48), we generally believe the risk of ischemia and liver failure is too high to pursue TACE in such patients. The Alberta HCC Algorithm, therefore, recognizes that TARE may be an option for intermediate stage HCC patients, especially for those with PVT (Figure 3). Currently, TARE is only offered in a few centres in Canada, which in Alberta includes Edmonton. TARE needs to be studied in RCTs against TACE (for BCLC stage B) and against sorafenib (for BCLC stage $\mathrm{C}$ ) to fully understand its role in the management of HCC. Currently, a health technology assessment and policy analysis of TARE is underway in Alberta.

\section{ADVANCED STAGE HCC (BCLC Stage C)}

Sorafenib is recommended for patients with advanced HCC (malignant portal vein invasion or extrahepatic disease) based on the results of two placebo-controlled RCTs $(49,50)$ that demonstrated improved overall survival in subjects who received this multikinase inhibitor that blocks proliferation (RAF kinase) and the receptors of vascular endothelial growth factor and platelet-derived growth factor. Sorafenib may also be used in BCLC stage B patients who have failed TACE or who are not candidates for TACE due to diffuse infiltrative disease or PVT. Compared with placebo, sorafenib increased survival (7.9 versus 10.7 months [HR 0.69; 95\% CI 0.55 to $0.87 ; \mathrm{P}<0.001]$ in the Sorafenib HCC Assessment Randomized Protocol (SHARP) [49], and 4.2 versus 6.5 months [HR 0.68; 95\% CI 0.50 to 0.93; P=0.014] in the Asia-Pacific study [50]). The lower overall survival rate in the Asia-Pacific study likely reflected the inclusion of more patients with advanced BCLC stage $\mathrm{C}$ disease (95\% versus $82 \%$ in the SHARP study). This oral chemotherapy agent is generally well tolerated, but is associated with the risk of hypertension, hand-and-foot reaction and diarrhea $(49,50)$. Both studies included only a very small 
number of patients with CTP class B cirrhosis (3\%) because this was an exclusion criterion for study entry $(49,50)$. Although the BCLC staging system recommends sorafenib chemotherapy for both CTP class A and B cirrhotic patients, further prospective studies in patients with CTP class B cirrhosis are needed before we can recommend its use in patients with more advanced liver disease.

The positive results of the SHARP study have led to renewed interest in pursuing targeted chemotherapy for HCC. Currently, sorafenib is being evaluated in RCTs as adjuvant therapy to prevent recurrence following surgical resection or RFA (BCLC stage A) in combination with TACE (BCLC stage $\mathrm{B}$ ) and, in combination with doxorubicin, other targeted therapies or TARE for patients with advanced HCC (BCLC stage C). Furthermore, several new agents (eg, brivinib and sunitinib) are being compared with sorafenib in ongoing phase III RCTs.

\section{END-STAGE HCC (BCLC STAGE D)}

Unfortunately, approximately 20\% of patients with HCC still present with end-stage disease and can only be offered palliative care (7). The Alberta HCC Algorithm recognizes that patients can progress to end-stage liver disease if they have advanced tumour characteristics in association with pronounced cancer-related symptoms (PS greater than 2), or in

\section{REFERENCES}

1. Parkin DM BF, Ferlay J, Pisani P. Global Cancer Statistics, 2002. CA Cancer J Clin 2005;55:74-108.

2. National Cancer Institute N, DHHS, Bethesda, MD. Cancer Trends Progress Report - 2009/2010 Update. <http://progressreport.cancer.gov>. (Accessed on September 30, 2010).

3. elSaadany S, Tepper M, Mao Y, Semenciw R, Giulivi A. An epidemiologic study of hepatocellular carcinoma in Canada. Can J Public Health 2002;93:443-6.

4. Pocobelli G, Cook LS, Brant R, Lee SS. Hepatocellular carcinoma incidence trends in Canada: Analysis by birth cohort and period of diagnosis. Liver Int 2008;28:1272-9.

5. El-Serag HB. Epidemiology of hepatocellular carcinoma in USA. Hepatol Res 2007;37(Suppl 2):S88-94.

6. Dixon E, Bathe OF, McKay A, et al. Population-based review of the outcomes following hepatic resection in a Canadian health region. Can J Surg 2009;52:12-7.

7. Bruix J, Sherman M. Management of hepatocellular carcinoma. Hepatology 2005;42:1208-36.

8. Llovet JM, Bru C, Bruix J. Prognosis of hepatocellular carcinoma: The BCLC staging classification. Semin Liver Dis 1999;19:329-38.

9. Llovet JM, Di Bisceglie AM, Bruix J, et al. Design and endpoints of clinical trials in hepatocellular carcinoma. J Natl Cancer Inst 2008;100:698-711.

10. Marrero JA, Fontana RJ, Barrat A, et al. Prognosis of hepatocellular carcinoma: Comparison of 7 staging systems in an American cohort. Hepatology 2005;41:707-16.

11. Toso C, Asthana S, Bigam DL, Shapiro AM, Kneteman NM. Reassessing selection criteria prior to liver transplantation for hepatocellular carcinoma utilizing the Scientific Registry of Transplant Recipients database. Hepatology 2009;49:832-8.

12. Alberta Health Services Clinical Practice Guidelines: Hepatocellular carcinoma. <www.albertahealthservices.ca/hp/ if-hp-cancer-guide-gi007-hepatocellular-carcinoma.pdf> (Accessed on October 5, 2010).

13. Yang HI, Sherman M, Su J, et al. Nomograms for risk of hepatocellular carcinoma in patients with chronic hepatitis B virus infection. J Clin Oncol 2010;28:2437-44.

14. Stigliano R ML, Yu D, Davies N, Patch D, Burroughs AK. Seeding following percutaneous diagnostic and therapeutic approaches for hepatocellular carcinoma. What is the risk and the outcome? Seeding risk for percutaneous approach of HCC. Cancer Treat Rev 2007;33:437-47.
CTP class C cirrhotic patients who are otherwise not candidates for LT. In general, such patients have a median survival rate that is typically less than three months (7).

\section{CONCLUSIONS}

The incidence of HCC is increasing in Canada; therefore, it is important that physicians familiarize themselves with the growing treatment options available for this malignancy. The management of HCC patients is best accomplished in a multidisciplinary manner. The BCLC staging system is preferred because it takes into account tumour, patient and liver characteristics and links them to specific therapies. The Alberta HCC Algorithm has improved on the BCLC staging system in several ways (Table 5), and better reflects our current clinical practice guidelines in Alberta (12). The management of HCC will continue to evolve as new information and therapeutic interventions become available in the future.

ACKNOWLEDGEMENTS: The authors thank Glenda Meeberg, from the University of Alberta Liver Transplant program, for providing data on LT activity for HCC patients in Alberta. They also acknowledge the work of the Alberta Provincial Gastrointestinal Tumour Team for the development of the Alberta Health Services Clinical Practice Guidelines (developed in August 2009 and updated in March 2010 [reference 12]).

15. Caturelli E, Solmi L, Anti M, et al. Ultrasound guided fine needle biopsy of early hepatocellular carcinoma complicating liver cirrhosis: A multicentre study. Gut 2004;53:1356-62.

16. Forner A, Vilana R, Ayuso C, et al. Diagnosis of hepatic nodules $20 \mathrm{~mm}$ or smaller in cirrhosis: Prospective validation of the noninvasive diagnostic criteria for hepatocellular carcinoma. Hepatology 2008;47:97-104.

17. Llovet JM, Fuster J, Bruix J. Intention-to-treat analysis of surgical treatment for early hepatocellular carcinoma: Resection versus transplantation. Hepatology 1999;30:1434-40.

18. Livraghi T, Meloni F, Di Stasi M, et al. Sustained complete response and complications rates after radiofrequency ablation of very early hepatocellular carcinoma in cirrhosis: Is resection still the treatment of choice? Hepatology 2008;47:82-9.

19. Mazzaferro V, Regalia E, Doci R, et al. Liver transplantation for the treatment of small hepatocellular carcinomas in patients with cirrhosis. N Engl J Med 1996;334:693-9.

20. Sumie S, Kuromatsu R, Okuda K, et al. Microvascular invasion in patients with hepatocellular carcinoma and its predictable clinicopathological factors. Ann Surg Oncol 2008;15:1375-82.

21. Chen MS, Li JQ, Zheng Y, et al. A prospective randomized trial comparing percutaneous local ablative therapy and partial hepatectomy for small hepatocellular carcinoma. Ann Surg 2006;243:321-8.

22. Lu MD, Kuang M, Liang LJ, et al. [Surgical resection versus percutaneous thermal ablation for early-stage hepatocellular carcinoma: A randomized clinical trial.] Zhonghua Yi Xue Za Zhi 2006;86:801-5.

23. Hasegawa K, Makuuchi M, Takayama T, et al. Surgical resection vs. percutaneous ablation for hepatocellular carcinoma: A preliminary report of the Japanese nationwide survey. J Hepatol 2008;49:589-94.

24. Cho YK, Kim JK, Kim MY, Rhim H, Han JK. Systematic review of randomized trials for hepatocellular carcinoma treated with percutaneous ablation therapies. Hepatology 2009;49:453-9.

25. Orlando A, Leandro G, Olivo M, Andriulli A, Cottone M. Radiofrequency thermal ablation vs. percutaneous ethanol injection for small hepatocellular carcinoma in cirrhosis: Meta-analysis of randomized controlled trials. Am J Gastroenterol 2009;104:514-24.

26. Lam VW, Ng KK, Chok KS, et al. Risk factors and prognostic factors of local recurrence after radiofrequency ablation of hepatocellular carcinoma. J Am Coll Surg 2008;207:20-9. 
27. Wang W, Shi J, Xie WF. Transarterial chemoembolization in combination with percutaneous ablation therapy in unresectable hepatocellular carcinoma: A meta-analysis. Liver Int 2010;30:741-9.

28. Toso C, Meeberg GA, Bigam DL, et al. De novo sirolimus-based immunosuppression after liver transplantation for hepatocellular carcinoma: Long-term outcomes and side effects. Transplantation 2007;83:1162-8.

29. Toso C, Merani S, Bigam DL, Shapiro AM, Kneteman NM. Sirolimus-based immunosuppression is associated with increased survival after liver transplantation for hepatocellular carcinoma. Hepatology 2010;51:1237-43.

30. Pelletier SJ, Fu S, Thyagarajan V, et al. An intention-to-treat analysis of liver transplantation for hepatocellular carcinoma using organ procurement transplant network data. Liver Transpl 2009;15:859-68.

31. Cucchetti A, Vitale A, Gaudio MD, et al. Harm and benefits of primary liver resection and salvage transplantation for hepatocellular carcinoma. Am J Transplant 2010;10:619-27.

32. Kim JM, Kwon CH, Joh JW, et al. Patients with unresectable hepatocellular carcinoma beyond Milan criteria: Should we perform transarterial chemoembolization or liver transplantation? Transplant Proc 2010;42:821-4.

33. Yao FY. Liver transplantation for hepatocellular carcinoma: Beyond the Milan criteria. Am J Transplant 2008;8:1982-9.

34. Toso C, Trotter J, Wei A, et al. Total tumor volume predicts risk of recurrence following liver transplantation in patients with hepatocellular carcinoma. Liver Transpl 2008;14:1107-15.

35. Lesurtel M, Mullhaupt B, Pestalozzi BC, Pfammatter T, Clavien PA. Transarterial chemoembolization as a bridge to liver transplantation for hepatocellular carcinoma: An evidence-based analysis. Am J Transplant 2006;6:2644-50.

36. Heckman JT, Devera MB, Marsh JW, et al. Bridging locoregional therapy for hepatocellular carcinoma prior to liver transplantation. Ann Surg Oncol 2008;15:3169-77.

37. Ioannou GN, Perkins JD, Carithers RL Jr. Liver transplantation for hepatocellular carcinoma: Impact of the MELD allocation system and predictors of survival. Gastroenterology 2008;134:1342-51.

38. Toso C, Mentha G, Kneteman NM, Majno P. The place of downstaging for hepatocellular carcinoma. J Hepatol 2010;52:930-6.

39. Llovet JM, Real MI, Montana X, et al. Arterial embolisation or chemoembolisation versus symptomatic treatment in patients with unresectable hepatocellular carcinoma: A randomised controlled trial. Lancet 2002;359:1734-9.

40. Lo CM, Ngan H, Tso WK, et al. Randomized controlled trial of transarterial lipiodol chemoembolization for unresectable hepatocellular carcinoma. Hepatology 2002;35:1164-71.

41. Llovet JM, Bruix J. Systematic review of randomized trials for unresectable hepatocellular carcinoma: Chemoembolization improves survival. Hepatology 2003;37:429-42.

42. Marelli L, Stigliano R, Triantos C, et al. Transarterial therapy for hepatocellular carcinoma: Which technique is more effective? A systematic review of cohort and randomized studies. Cardiovasc Intervent Radiol 2007;30:6-25.

43. Robbins SC, Sadler D, Wong J, et al. Transarterial chemoembolization for hepatocellular carcinoma: A single centre experience and quality assurance project. Can J Gastroenterol 2009;23:110A. (Abst)

44. Robbins SC, Sadler D, Wong J, et al. Total tumour volume and alfa-fetoprotein (AFP) but not type of embolic agent predict survival after transarterial chemoembolization of hepatocellular carcinoma. International Liver Cancer Association Meeting, September 4 to 6, 2009.

45. Varela M, Real MI, Burrel M, et al. Chemoembolization of hepatocellular carcinoma with drug eluting beads: Efficacy and doxorubicin pharmacokinetics. J Hepatol 2007;46:474-81.

46. Lammer J, Malagari K, Vogl T, et al. Prospective randomized study of doxorubicin-eluting-bead embolization in the treatment of hepatocellular carcinoma: Results of the PRECISION V study. Cardiovasc Intervent Radiol 2010;33:41-52.

47. Salem R, Lewandowski RJ, Mulcahy MF, et al. Radioembolization for hepatocellular carcinoma using Yttrium-90 microspheres: A comprehensive report of long-term outcomes. Gastroenterology 2010;138:52-64.

48. Georgiades CS, Hong K, D'Angelo M, Geschwind JF. Safety and efficacy of transarterial chemoembolization in patients with unresectable hepatocellular carcinoma and portal vein thrombosis. J Vasc Interv Radiol 2005;16:1653-9.

49. Llovet JM, Ricci S, Mazzaferro V, et al. Sorafenib in advanced hepatocellular carcinoma. N Engl J Med 2008;359:378-90.

50. Cheng AL, Kang YK, Chen Z, et al. Efficacy and safety of sorafenib in patients in the Asia-Pacific region with advanced hepatocellular carcinoma: A phase III randomised, double-blind, placebo-controlled trial. Lancet Oncol 2009;10:25-34. 


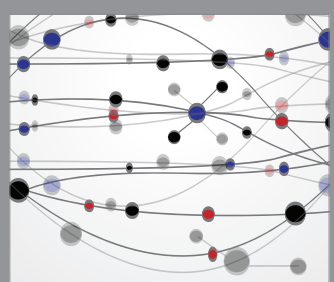

The Scientific World Journal
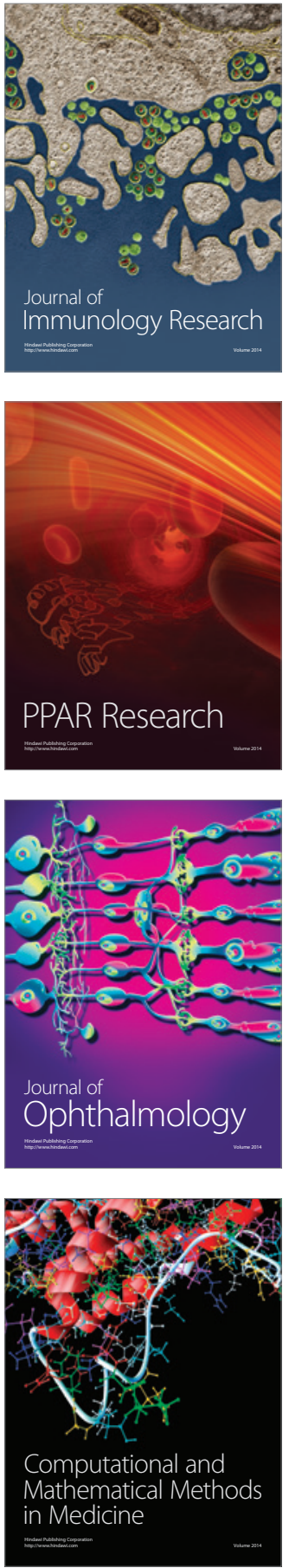

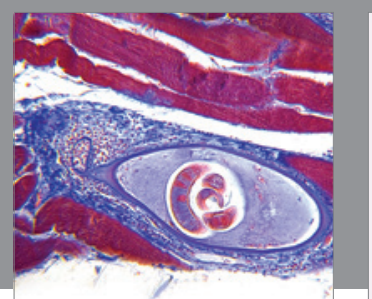

Gastroenterology Research and Practice

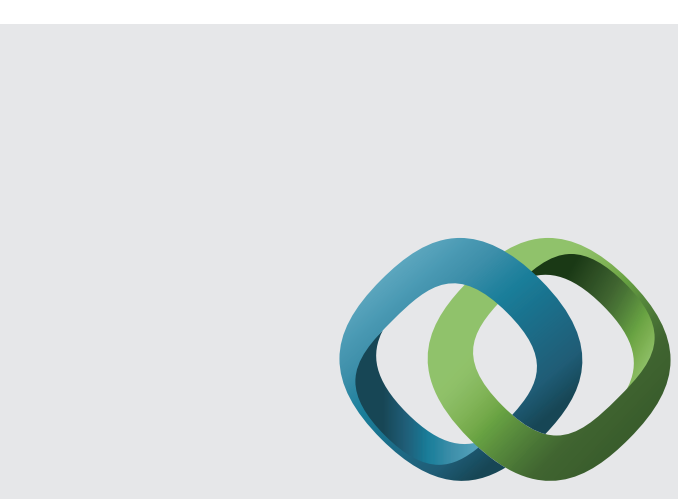

\section{Hindawi}

Submit your manuscripts at

http://www.hindawi.com
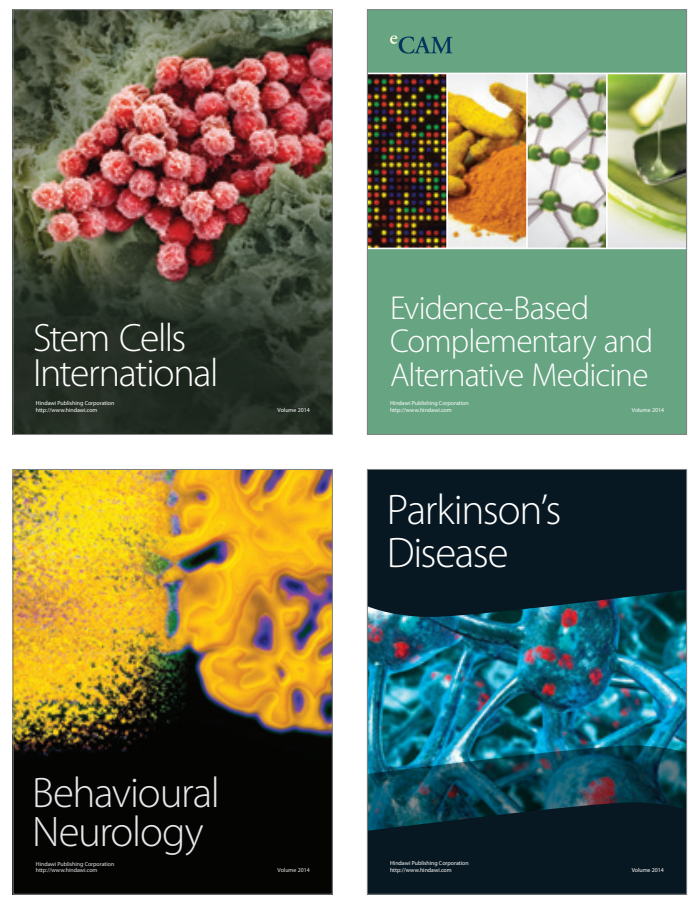
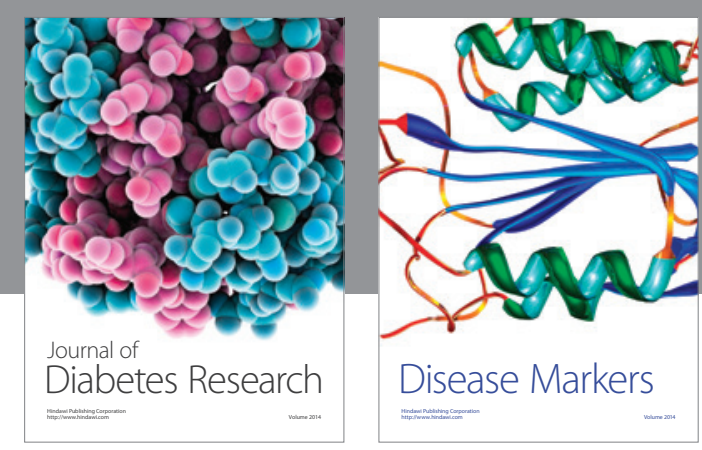

Disease Markers
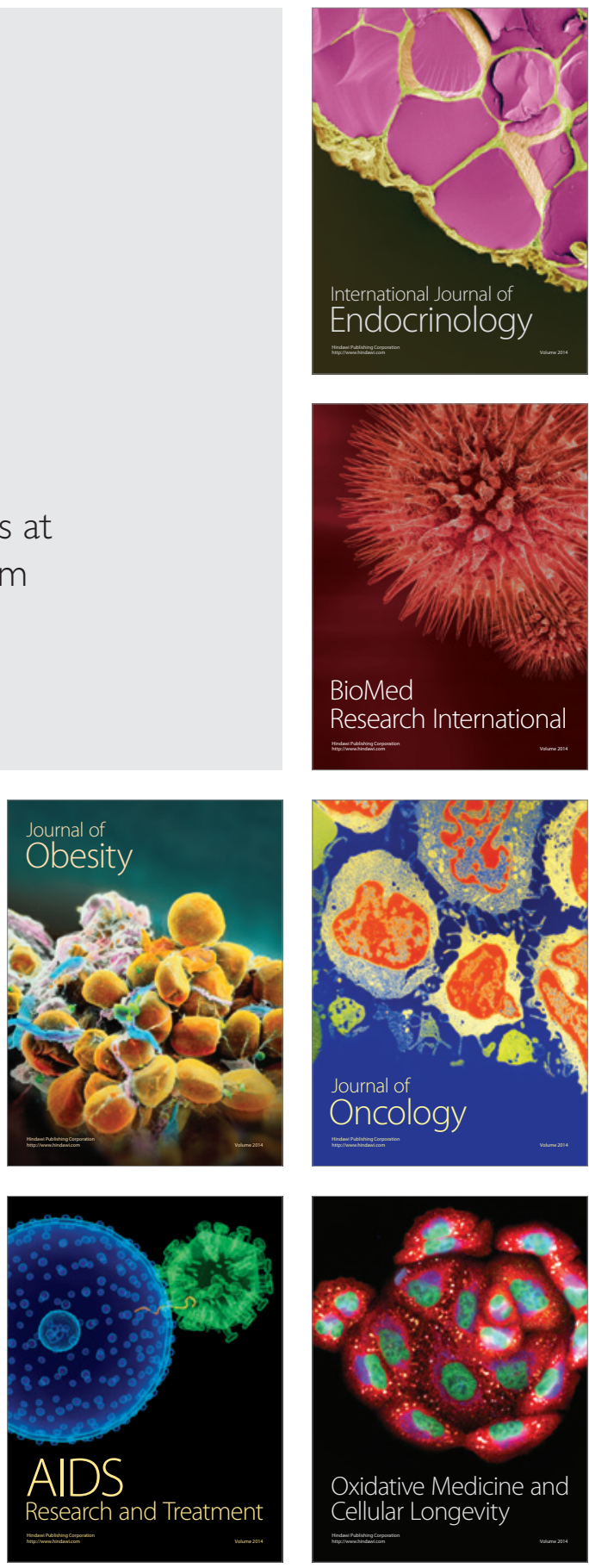